\title{
LOS ORÍGENES DEL LAZARETO PABELLONARIO. LA ARQUITECTURA CUARENTENARIA EN EL CAMBIO DEL SETECIENTOS AL OCHOCIENTOS
}

\author{
Quim Bonastra \\ Departamento de Geografía y Sociología. Universitat de Lleida
}

\begin{abstract}
RESUMEN
El modelo de lazareto pabellonario se configuró a partir de las bases científicas establecidas durante el proceso de reforma hospitalaria acaecido en Francia en el último tercio del setecientos. La adopción de soluciones que dieran forma a la nueva tipología cuarentenaria no vino dada precisamente por el ejemplo prestado por los nuevos tipos de hospital resultantes de este debate sino por el de otras instalaciones de cuarentena y, en general, de encierro, ya existentes. En este artículo se analizarán todos los factores que influyeron en la configuración de este modelo de lazaretos.
\end{abstract}

PALABRAS CLAVE: Lazareto, Pabellones, Cuarentena, Peste, Fiebre Amarilla, España, Francia, Italia, Siglo XVIII, Siglo XIX.

THE ORIGINS OF THE PAVILION LAZARETTO. QUARANTINE ARCHITECTURE BETWEEN THE $18^{\mathrm{TH}}$ AND $19^{\mathrm{TH}}$ CENTURIES

\begin{abstract}
The model of pavilion lazaretto was built above the scientific basis established during the hospital reform process held in France on the lasts decades of Eighteenth Century. The morphological solutions adopted for the new quarantine taxonomy has not been given by the example borrowed by the new typology of hospital as resulted in this discussion, but by existing quarantine and detention facilities in general. In this paper we will analyse all factors that have influenced in the configuration of this model of lazarettos.
\end{abstract}

KEY WORDS: Lazaretto, Pavilion, Quarantine, Plague, Yellow Fever, Spain, France, Italy, $18^{\text {th }}$ Century, $19^{\text {th }}$ Century.

\section{INTRODUCCIÓN}

Es difícil encontrar, en la historia de las tipologías hospitalarias, un modelo tan bien documentado como el de pabellones en Francia, puesto que fue el 
fruto de años de debate. El investigador puede trazar con bastante precisión sus orígenes, sus influencias y los actores que participaron en su configuración, gracias a las múltiples memorias, informes y proyectos que dicha discusión generó. Cuando hablamos de lazaretos pabellonarios, si bien éstos coinciden en las ideas de fondo con el de esta categoría de hospitales, nos damos cuenta de que los modelos en los que se inspiraron los primeros para dar soluciones de configuración no se corresponden estrictamente con los que sirvieron de ejemplo a los segundos. En este artículo intentaremos sentar las bases sobre las que se asienta este tipo de lazaretos, para lo cual haremos un repaso de las bases teóricas proporcionadas por el debate sobre los hospitales, nos fijaremos en las construcciones que inspiraron ambos tipos de edificio y acudiremos, cuando sea necesario, a las doctrinas médicas sobre las que, tanto unos como otros, estaban fundados en un viaje que nos llevará por proyectos de lazareto españoles, franceses e ingleses.

\section{LAS BASES TEÓRICAS, EL DEBATE SOBRE EL NUEVO HôTEL-DIEU DE PARÍS}

El treinta de diciembre de 1772 se incendió el Hôtel-Dieu de París, un gran hospital construido durante siglos a base de aditamentos y que era un claro exponente de institución en la cual se mezclaban la función asistencial y médica $^{1}$. Tras este accidente se puso de manifiesto la insuficiencia del modelo de hospital entonces vigente y la necesidad de crear nuevas infraestructuras para la ciudad que ocupasen el vacío dejado por el establecimiento quemado, lo que provocó un debate sobre los principios que debían regir este tipo de entidades. Éstas se convertirían, a partir de ese momento y rompiendo con los postulados vigentes, en un equipamiento sanitario de la ciudad en el sentido moderno del término ${ }^{2}$. En este proceso, el hospital se desprendió del hospicio

1 «... cet Hôpital est l'Hôtel-Dieu ; on y est reçu à toute heure, sans acception d'âge, de sexe de pays, de religion; les fiévreux, les blessés, les contagieux, les non-contagieux, les fous susceptibles de traitement, les femmes \& les filles enceintes y sont admis : il est donc l'Hôpital de l'Homme nécessiteux \& malade, nous ne disons pas seulement de Paris, \& de la France, mais du reste de l'Univers ». TenON, J. (1788), Mémoires sur les hôpitaux de Paris. Paris: chez Royez, p. j.

2 En París, explica Tenon, existían en esa época cuarenta y ocho hospitales, de los cuales veintidós se utilizaban exclusivamente para acoger enfermos, seis servían para el recogimiento de pobres enfermos y pobres sanos y veinte se utilizaban para la acogida de pobres sanos. Para una sucinta descripción de cada uno de estos hospitales ver TENON (1788), p. 3-25. Sobre el concepto de equipamiento ver FORTIER, B. (1979), «Le camp et la forteresse inversée». En 


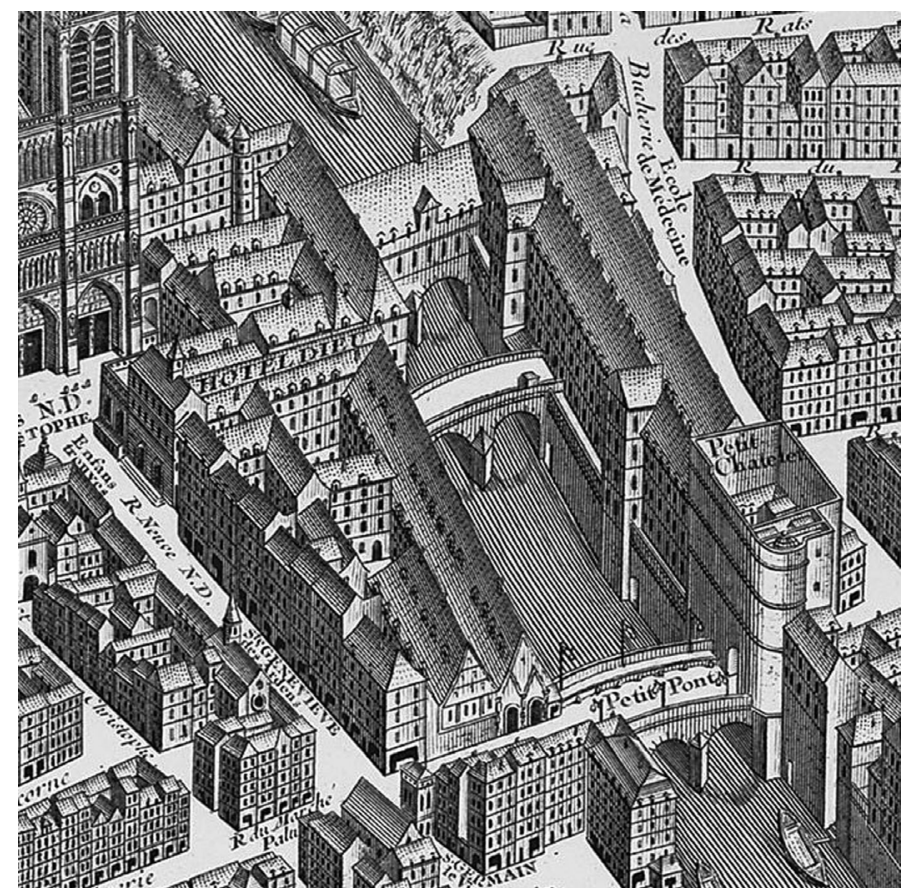

Figura 1. Vista de Pájaro del Hôtel-Dieu de París a mediados del siglo XVIII

Fuente: Plan de Paris commencé l'année 1734. Dessiné et Gravé, sous les ordres de Messire Michel Étienne Turgot (...) achevé de graver en 1739. Detalle de la plancha $\mathrm{n}^{\circ} 11$.

y se constituyó como un espacio solamente médico ${ }^{3}$, evolución lógica del pensamiento nosológico ${ }^{4}$ - que en su aplicación social no podía permitir la

FOUCAULT et al. Les machines à guérir (aux origines de l'hôpital moderne). Bruxelles: Pierre Mardaga, p.45-50; FORTIER, B. (1980), «Storia e pianificazione urbana: gli anni 1800». En Morachiello, P. y Teyssot, G. Le macchine imperfette. Architettura, programma, istituzioni, nel XIX secolo. Roma: Officina Edición, p. 27-55.

3 Esta operación comportaba tres requisitos fundamentales, la valoración de la salud de los individuos, la cuantificación de las necesidades médicas y la concepción de la población como objeto de conocimiento médico, ver BARRET KRIEGEL, B. (1979), «L'hôpital comme équipement». En FouCAUlt, M. et al., Les machines à guérir (aux origines de l'hôpital moderne). Bruxelles: Pierre Mardaga, p. 19-30, p. 19 y ss.

4 Ver el primer capítulo de FouCAUlt, M. (1963), Naissance de la clinique. Paris: PUF. 
mezcla de la enfermedad con la pobreza o la vagancia-, y surgieron nuevas formas arquitectónicas que servirían para todo el siglo siguiente.

El debate entablado en torno al nuevo Hôtel-Dieu de París supuso, para las tipologías hospitalarias, la puesta en escena y el modelado del hospital pabellonario. Confluían en su sistematización varios elementos que configurarían el nuevo paradigma: por un lado, la conservación de un aire puro en el interior del recinto y el cuidado de la salubridad en general. Por otro, la separación de los diferentes tipos de enfermos y la separación, también, de los diferentes servicios del hospital. Y, finalmente, la atención al problema de la circulación, de los flujos internos del hospital.

En 1777, impulsada por Jacques Necker, el nuevo Director General de Finanzas, se creó una comisión encargada de examinar los medios de mejorar los hospitales de París y de reformar el Hôtel-Dieu. En el mismo sentido, en agosto de ese mismo año, la comisión abrió un concurso público de propuestas. Llamamiento que obtuvo una respuesta más que considerable con más de ciento cincuenta proyectos recibidos.

Entre estos proyectos se encontraba el de Jean-Baptiste Le Roy ${ }^{5}$, que inspiraría el adoptado más tarde por la Académie Royale des Sciences y que estaba basado en el principio de conservar: «autant qu'il est possible un air pur et exempt de la corruption qui règne toujours dans les hôpitaux nombreux» ${ }^{6}$. Para ello consideraba que:

Pour se former donc une idée de l'hôpital que je propose, il faut s'en représenter les différentes salles comme entièrement isolées, et rangées comme les tentes dans un camp, ou comme les pavillons des jardins de Marly; on les voit ainsi rangées dans l'élévation de mon hôpital, prise sur la longueur. Par cette disposition, chaque salle est comme une espèce d'île dans l'air, et environnée d'un volume considérable de ce fluide, que les vents pourront emporter et renouveler facilement par le libre accès qu'ils auront tout autour. Cet air, étant ainsi renouvelé, servira ensuite à renouveler celui des salles, sans que le mauvais air des uns puisse être reporté dans les autres ${ }^{7}$.

5 El proyecto de Le Roy no se publicaría hasta doce años más tarde, en la las Memorias de la Academia correspondientes al año 1787: LE RoY, J.-B. (1789), «Précis d'un ouvrage sur les hôpitaux dans lequel on expose les principes résultants des observations de Physique et de Médecine qu'on doit avoir en vue dans la construction de ces édifices; avec un projet d'hôpital disposé selon ces principes». Mémoires de l'Académie Royale des Sciences, Année 1787, p. 585-600.

$\begin{array}{ll}6 & \text { Le RoY (1789), p. } 593 . \\ 7 & \text { LE RoY (1789), p. } 594 .\end{array}$ 


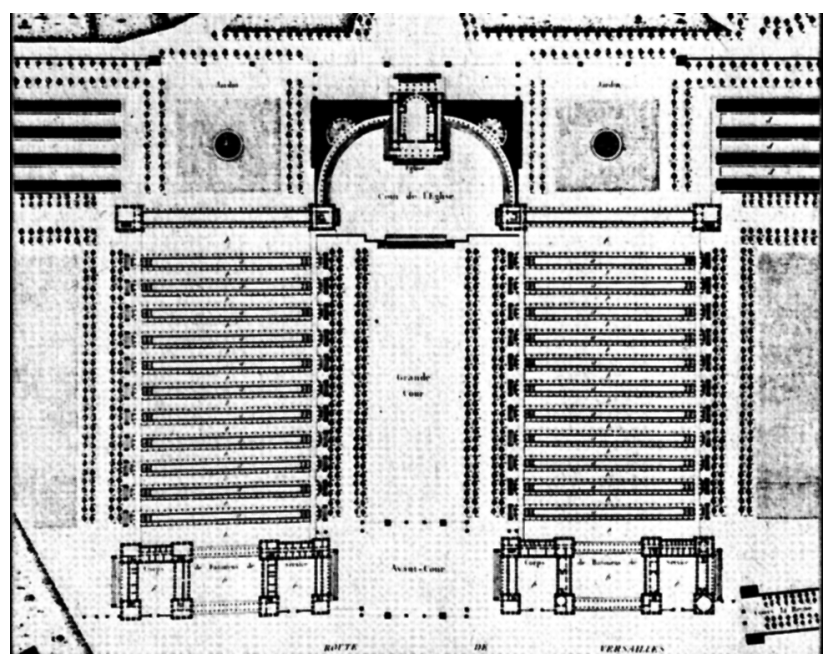

FIGURA 2. Proyecto de hospital en pabellones, por Jean-Baptiste Leroy (detalle)

Fuente: LE ROY (1789)

La ventilación de las estancias era un tema que en esa época había ido adquiriendo importancia ${ }^{8}$ puesto que, como muchos de los estudiosos de aquel entonces reconocían, los hospitales, lejos de ser lugares en los que se efectuara la curación de los convalecientes, se habían vuelto una fuente de contagio. El hospital aún vigente a finales del setecientos era malsano a causa de su sobreocupación, pero lo era también a causa de su errónea concepción arquitectónica y funcional, constelación causal que impedía el mantenimiento de un aire puro en el interior de los edificios. De este modo, en su plan, Le Roy tenía en cuenta la renovación del aire dentro de cada uno de los pabellones, dando diferentes soluciones arquitectónicas y mecánicas, que impedirían incluso el contagio de males entre diferentes pacientes de una misma sala. Me-

8 De este modo no es extraño que a lo largo del setecientos hubiesen visto la luz diversos tratados, memorias y artículos que incidían sobre esta temática referidos tanto a los hospitales como a los domicilios particulares, ver, por ejemplo, DU HAMEL, H.-L. (1752), «Différens moyens pour renouveler l'air des Infirmeries, \& généralement de tous les endroits où le mauvais air peut incommoder la respiration». Mémoires de l'Académie Royale des Sciences, Année 1748, p. 1-10; PATTE, P. (1769), Mémoires sur les objets les plus importans de l'architecture. Paris: Rozet; PETIT, A. (1774), Projet et mémoire sur la meilleure manière de construire un hopital de malades. Paris: Imp. Louis Cellot. 
diante murillos que separarían las camas y chimeneas en los techos se aseguraría un higiénico movimiento continuo de aire de abajo hacia arriba ${ }^{9}$.

En 1784 la comisión formada a instancias de Necker fue disuelta por el Secretario de Estado Breteuil y el asunto pasó a manos de la Académie Royale des Sciences ${ }^{10}$. A los tres proyectos entre los que se debatía la nueva comisión $^{11}$, se sumó en 1785 un nuevo proyecto que provocó un intenso debate, se trata del proyecto del arquitecto Bernard Poyet ${ }^{12}$ que era el «Contrôleur des Bâtiments de la Ville» de París. La querella provocó la redacción de una primera memoria ${ }^{13}$ por parte de los comisarios de la Academia en la que se examinaban, por una parte, el Hôtel-Dieu y el resto de hospitales de París y, por otra, el proyecto de Poyet ${ }^{14}$, elogiado pero criticado por el lugar propuesto para su construcción ${ }^{15}$ y por ciertos aspectos de la disposición del edificio,

9 Es conocido el interés que Le Roy tenía sobre este particular, ver, por ejemplo: LE RoY, J.-B. (1784), «Mémoire sur quelques moyens simples de renouveler l'air des endroits dans lesquels il ne circule pas, ou dans lesquels il ne circule que très-difficilement; $\&$ sur les applications qu'on peut en faire». Histoire de l'Académie Royale des Sciences, Année 1780, p. 598-602; sabemos, además, que mantuvo durante la década de 1770 y 1780 una estrecha correspondencia con Benjamin Franklin sobre la construcción de hospitales y sobre su ventilación y que tradujo al francés diversas memorias de médicos extranjeros sobre estos temas, ver Greenbaum, L. S. (1974), «Tempest in the Academy. Jean-Baptiste Le Roy, the Paris Academy of Sciences and the Project of a new Hôtel-Dieu». Archives Internationales d'Histoire des Sciences, 24, p. 122-140, p. 125.

10 La nueva comisión estaba formada por Joseph-Marie-François de Lassone, LouisJean-Marie Daubenton, Jacques Tenon, Jean-Sylvain Bailly, Antoine-Laurent de Lavoisier, Pierre-Simon de La Place, Charles-Augustin de Coulomb, Jean d'Arcet y Jean-AntoineNicolas de Condorcet.

11 Se trataba de los proyectos de Jean-Baptiste Le Roy (LE Roy (1789)), Antoine Petit (Petit (1774)) y Hugues Maret (MARET, H. (1783), «Mémoire sur la construction d'un hôpital». Nouveaux Mémoires de l'Académie de Dijon, Année 1782, 1, $1^{\mathrm{er}}$ semestre.).

12 Poyet, B. (1785), Mémoire sur la nécessité de transférer et reconstruire l'Hôtel-Dieu de Paris, suivi d'un projet de translation de cet hôpital. Paris: Chambre des Députés.

13 Lassone, Daubenton, Tenon, Bailly, Lavoisier, La Place, Coulomb, D’arcet (1788a), «Rapport des Commissaires chargés par l'Académie, de l'examen du Projet d'un nouvel Hôtel-Dieu». Historie de l'Académie Royale des Sciences, Année 1785, p. 2-110.

14 El proyecto de Poyet es bien conocido, se trata de un modelo radial concéntrico en forma de rueda muy parecido al de Antoine Petit.

15 El sitio era la Île des Cygnes, que se inundaba periódicamente, cosa que implicaría un gran gasto en las obras para evitar el anegamiento del edificio y la comodidad de su acceso en todo momento y que, además, comportaba una lejanía excesiva de ciertos barrios de la ciudad. LASSONE et al. (1788a), p. 84. 
principalmente su gran extensión ${ }^{16}$, la proyección de tres plantas ${ }^{17}$ y su excesiva altura. Finalmente, lanzaban su propia propuesta que consistía en la división de la atención hospitalaria de París entre cuatro edificios - con una capacidad de 1200 enfermos cada uno- situados en sendos extremos de la ciudad, cerca de donde eran necesarios. En lo que respecta a su disposición consideraron acertadas las proposiciones de Le Roy. Leamos las palabras de los comisarios:

«Au lieu d'enfermer une cour par trois ou quatre corps-de-logis, on peut les développer, les isoler, les espacer. Nous proposons que ces bâtiments soient des parallèles, auxquelles on donnera la longueur qu'on voudra, \& que nous supposons ici de 110 à 120 toises : ces parallèles seront séparés par des cours de la même longueur, \& larges de 20 à 30 toises, qui formeront de vastes promenoirs» ${ }^{18}$.

Tomada una primera posición convenía reafirmar las ideas, para lo que la Commission des Hôpitaux puso en marcha una encuesta ${ }^{19}$ en la que, por un lado, recogió las observaciones de la Académie de Marine sobre los barcos, los lazaretos y los hospitales militares, por otro lado, envió a cada uno de los Intendentes un cuestionario en el que se tenía que dar cuenta de los establecimientos de caridad de las principales ciudades del país. En el mismo sentido, se adquirieron los planos y descripciones de varios hospitales de Italia y de Alemania; se envió a Tenon y a Coulomb a Inglaterra y Holanda para «visiter les hôpitaux, en remarquer les avantages \& les inconvéniens, afin de se

16 «... un hôpital, quel que bien tenu qu'il soit, est toujours un réceptacle de maux et de misère. C'est un tableau effrayant de considérer ces maux au nombre de 5000 ; de penser qu'on charge ainsi sans cesse un même volume d'air, non seulement des émanations de 5000 individus, mais des miasmes \& de l'infection de ces corps malades, dont le lieu les plus aéré $\&$ une propreté toujours vigilante, ne peuvent entièrement les dépouiller (...) Si cette machine vaste $\&$ compliquée étoit absolument nécessaire, ce seroit un malheur de plus à compter dans les misères humaines qui naissent dans l'état de société». LASSONE et al. (1788a), p. 85-86.

17 «Nous pensons cependant que l'on ne doit point placer trois étages de salles les uns sur les autres. C'est un des défauts que nous avons reprochés à l'Hôtel-Dieu. On s'élève ainsi pour épargner sur la superficie ; mais le service est plus gêné, mais les convalescents sont plus fatigués, quand il s'agit de monter \& de descendre, mais il y a l'inconvénient du feu, \& du danger des malades à cette hauteur». LASSONE et al. (1788a), p. 82.

18 LASSONE et al. (1788a), p. 96. Conviene añadir que además se tenía en cuenta la orientación de los pabellones, que se preveía de este a oeste para aprovechar adecuadamente las características de los vientos dominantes en la ciudad.

19 Ver Foucault et al. (1979), p. 54-56. 
procurer ces avantages, \& d'eviter les inconvéniens» ${ }^{20}$ y se organizó un nuevo concurso de ideas para acabar de definir la planta del establecimiento tipo, las premisas eran regularidad, partición estricta de los espacios y sobriedad.

En resumen, convenía elegir entre el modelo en pabellones, lanzado por Le Roy y considerado como bueno por la comisión, y el de fortaleza invertida o panóptico, propuesto por Poyet o Petit, de cuya crítica ya se ha dado cuenta. Esta elección se debía hacer siguiendo unas nuevas normas en cuya base se encontraban los principios médicos y las necesidades de la práctica de la medicina, factores que necesariamente tenían que definir el diseño, la talla y el funcionamiento del nuevo hospital. Esto debía conseguirse con razonamientos que debían emanar de una aproximación al objeto de estudio asentada sobre el rigor metodológico, el empirismo cauteloso y la exacta cuantificación de las necesidades que dieran validez científica, tanto a las críticas del antiguo modelo de hospital, como al nuevo que la Academia debía proponer ${ }^{21}$. Como consecuencia de este celo científico se puso en marcha la gran encuesta en la que se analizaron los edificios existentes, se tomó en cuenta la experiencia de otros servicios asistenciales como el de la Académie de Marine, se buscó inspiración en los hospitales extranjeros y se solicitaron ideas públicamente, siguiendo los principios empíricos y analíticos de pensadores como Bacon, Condillac o Newton.

Estas ideas se publicaron paralelamente en la tercera memoria de la comisión y en un volumen redactado por Tenon ${ }^{22}$, obras, ambas, que sirven como marco conceptual del nuevo modelo de hospital que resultaría de esta vasta encuesta. Así, se substituía la intención tradicional del edificio, que aislaba y encarcelaba la enfermedad - y también la pobreza y todo aquello que en términos generales era considerado como una lacra social-, por la de un equipamiento para la ciu$\mathrm{dad}^{23}$, adecuado a las necesidades reales de la población y colocado allí donde era necesario, un servicio - en el sentido actual del término- situado en la confluencia de las políticas urbanas y de las estrategias médicas ${ }^{24}$.

20 Lassone, Daubenton, Bailly, Lavoisier, La Place, D’arcet (1788b), «Deuxième Rapport des Commissaires chargés, par l'Académie, des Projets relatifs à l'établissement des quatre Hôpitaux». Historie de l'Académie Royale des Sciences, Année 1786, p. 1-12, p. 12.

21 Greenbaum, L. S. (1975), "'Measure of civilization': The Hospital Thought of Jacques Tenon on the Eve of the French Revolution». Bulletin of the History of Medicine, 24 (1), p. 43-56, p. 44-46.

22 Respectivamente, LASSONE et al. (1788c) y TENON (1788).

23 BARRet Kriegel (1979), p. 28.

24 ForTiER, B. (1980), «Storia e pianificazione urbana: gli anni 1800». En MorACHIELLO, P y TeYssot, G. (Eds.), Le macchine imperfette. Architettura, programma, istituzioni, nel XIX secolo. Roma: Officina Editori, p. 27-55, p. 39. 


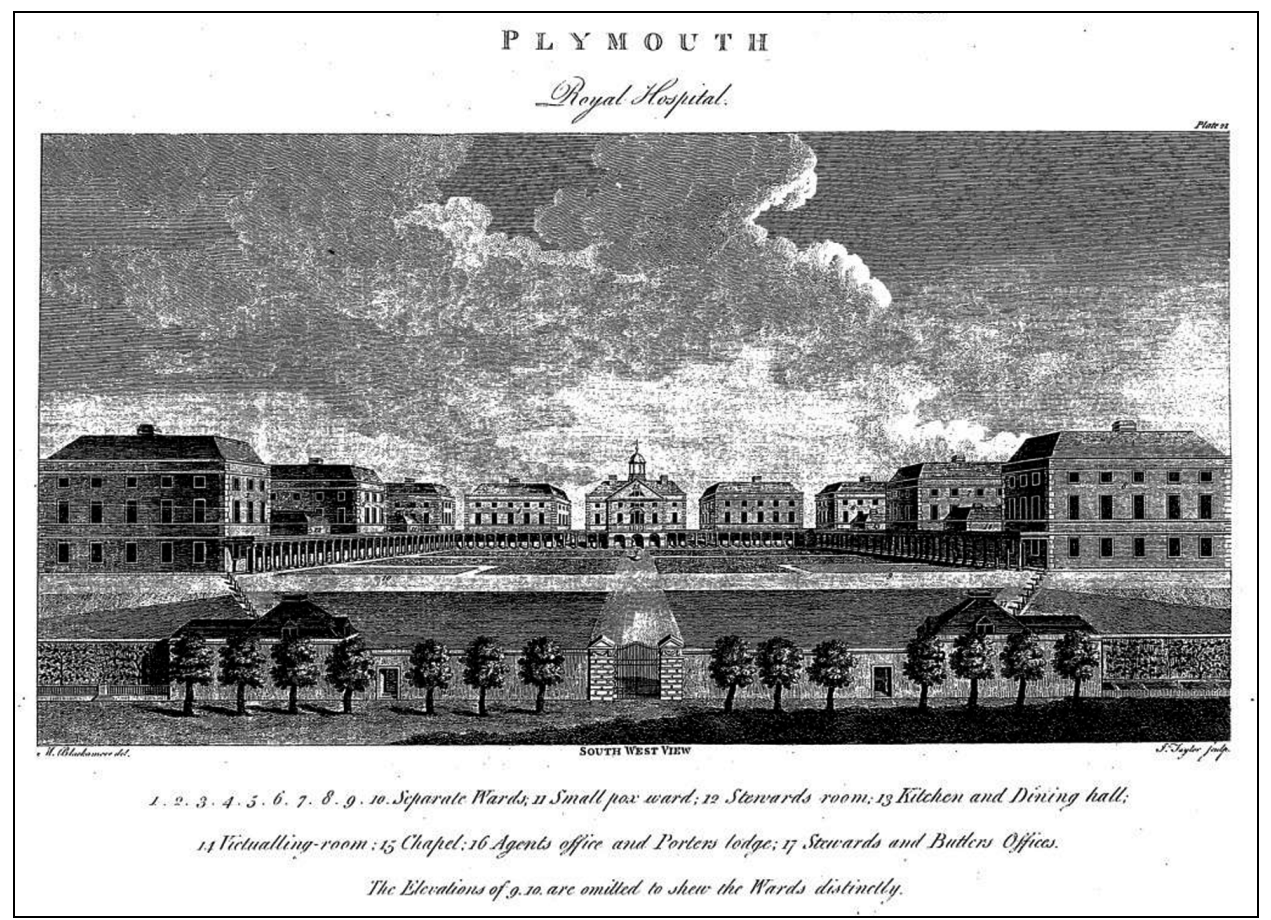

FIGURA 3. Vista del Royal Naval Hospital de Plymouth a finales del siglo XVIII. Fuente: HOWARD, J. (1784), Appendix to the State of the Prisons in England and Wales, $\& c$., containing a farther account of Foreign Prisons and Hospitals... Warrington: William Eyres, plancha 21.

El resultado de la encuesta es conocido. La comisión, siguiendo el parecer de la Academia, se inclinó por la disposición de edificios en líneas paralelas. Solamente faltaba fijar su planta definitiva prestando especial atención a los resultados de la encuesta. En este sentido, la ratificación de la conveniencia del modelo en pabellones vino dada por el ejemplo del hospital naval de Plymouth ${ }^{25}$. Ade-

25 «... celui de Plimouth, composé de pavillons isolés, \& rangés autour d'une cour trèsvaste, a une disposition presque semblable à celle que nous avions déjà préférée (...). Cet hôpital est donc un témoin subsistant, \& depuis vingt-quatre ans, de la salubrité qu'auront les nouveaux hôpitaux dont nous proposons les dispositions» en LASSONE, DAUBENTON, TILLET, TENON, BAILly, LAVOISIER, LA Place, COUlOMB, D’ARCET (1788c), «Troisième Rapport des Commissaires chargés, pal l'Académie, de l'examen des projets relatifs à l'établissement des quatre Hôpitaux». Historie de l'Académie Royale des Sciences, Année 1786, p. 13-43, p. 16. 
más, de los hospitales ingleses, se trajo también la ratificación de algunas de las ideas lanzadas en la crítica del Hôtel-Dieu, como la ventaja que suponía el acogimiento de un pequeño número de enfermos en cada sala, el hacer lavar a los convalecientes a su entrada al hospital, el de procurar los medios parar hacer renovar el aire de las salas del complejo o el mantenimiento de su limpieza.

Volvamos a la distribución interior del nuevo modelo de hospital cuya originalidad radicaba en su mirada funcionalista ${ }^{26}$, si el viejo Hôtel-Dieu quedaba descentralizado y se separaban las funciones asistenciales de las médicas, en el interior de cada uno de los nuevos edificios ocurría lo mismo. Se presentó un proyecto ${ }^{27}$ en el que, al igual que en el de Le Roy, se prestaba una atención especial a la salubridad del complejo, sobre todo en lo que se refería a la circulación del aire. Esto se tenía que conseguir mediante la disociación de los servicios del hospital en diferentes pabellones, con lo cual se obtendría la separación necesaria para que cada uno de los módulos estuviese envuelto en todo momento por un aire puro y renovado, cada pabellón tendría su propio «promenoir» y cada uno de estos subconjuntos podría ser incomunicado a voluntad $^{28}$. El hombre y sus necesidades como enfermo se convertían en la vara de medir del complejo, y eran éstas las que dictaban sus dimensiones, tanto en lo relativo al conjunto como en lo que tocaba al interior de cada uno de los pabellones, la amplitud de sus salas, la anchura de las escaleras, la altura de sus peldaños, etc. ${ }^{29}$. Además, se presentaron cálculos volumétricos que ayudaban a establecer la relación entre el número de camas y las dimensiones de cada pabellón, para que cada paciente gozara de los mínimos de aire puro necesario, relación que, por otra parte, se tendría que adecuar a las características ambientales, e incluso culturales, de cada región o país.

26 Este modelo de complejo en pabellones con las funciones separadas ya se estaba aplicando en Francia en otro tipo de establecimientos, recordemos el complejo industrial de las Salines Royales de Chaux diseñado por Claude-Nicolas Ledoux.

27 El dibujo de su planta fue encargado al arquitecto Bernard Poyet.

28 LASSONE (1788c), p. 36.

29 «Il s'agissoit de l'homme, \& de l'homme malade : sa stature régle la longueur du lit, la largeur des salles; son pas, moins étendu, moins libre que celui de l'homme sain, donne la hauteur des marches, comme la longueur du brancard, sur lequel on le transporte, détermine la largeur des escaliers d'Hôpitaux. D'ailleurs, consommant plus ou moins d'air dans un temps donné, selon que ses maladies l'obligent à des inspirations plus ou moins fréquentes \& plus ou moins amples, il demande des salles de dimensions différentes ; ajoutez que ses yeux sensibles aux impressions de la lumière durant les inflammations de la dure-mère $\&$ les violentes ophtalmies, exigent des attentions, relativement à la position, tant des lits que des croisés». TENON (1788), p. ix-x. 


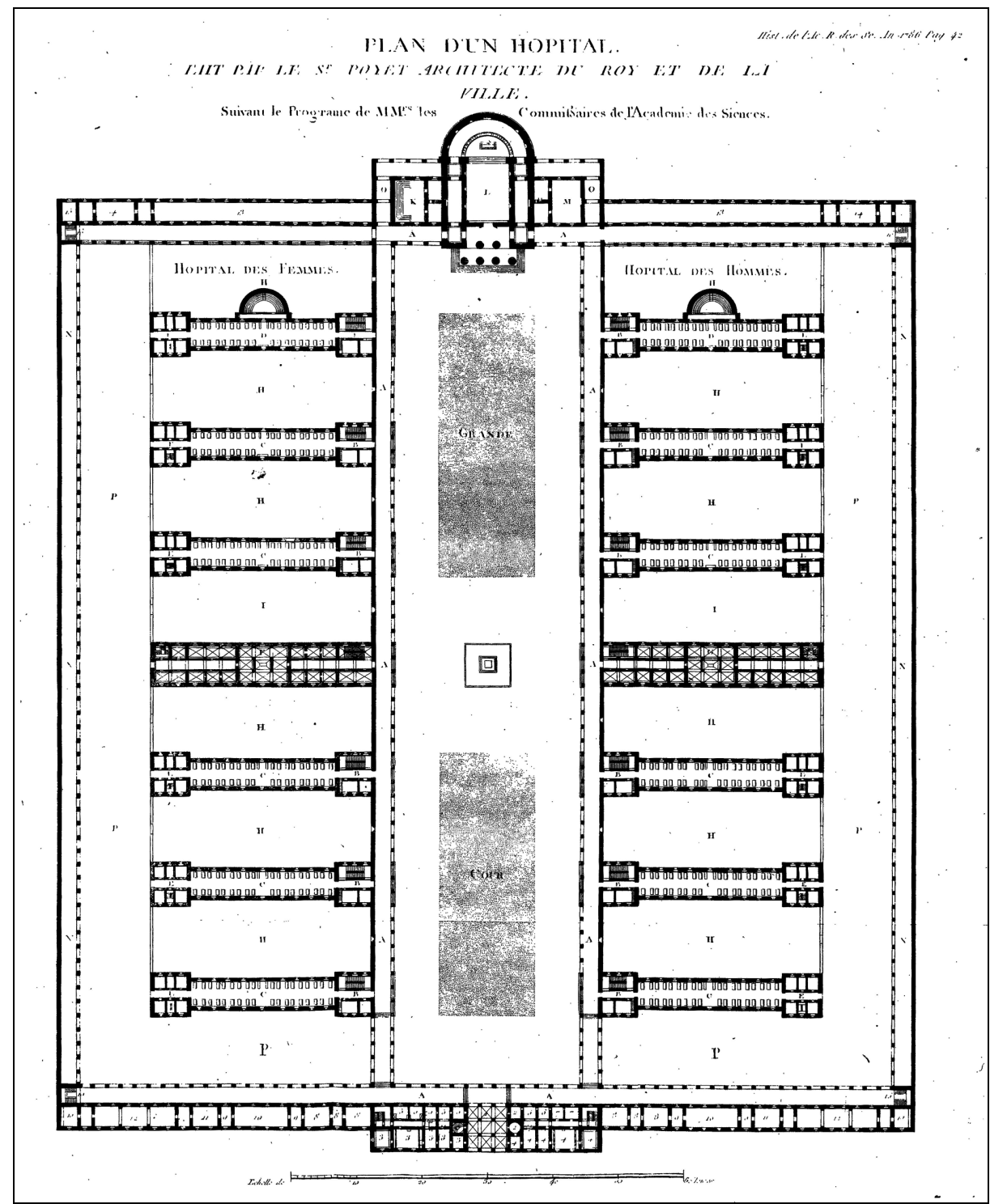

FiguRA 4. Plan d'un Hôpital fait par le Sr. Poyet, Architecte du Roy et de la Ville. Suivant le programe de MMrs. les Commissaires de l'Academie des Sciences.

Fuente: LASSONE (1788c) 
El hospital se tornaba, gracias a su fragmentación, en el contenedor de la práctica nosológica. Los enfermos serían clasificados en el departamento correspondiente a su dolencia. De este modo, cada pabellón sería un hospital separado, segregado funcionalmente del resto, pero compartiendo los servicios comunes y las subdivisiones en el seno del complejo vendrían marcadas por el conocimiento del número de enfermos que podían suministrar cada especie de enfermedad ${ }^{30}$. La planta del nuevo modelo de hospital estaba fundado en la cuantificación de las necesidades médicas, en la clasificación de las enfermedades y en la separación y aislamiento de las funciones hospitalarias.

Lógicamente, esto comportaba una fuerte estructuración del complejo y la colocación de los servicios y compartimentos quedaba condicionada a los ejes de desplazamiento. En este sentido, se observaba cuidadosamente la organización de los flujos de circulación en el seno del hospital, cosa que comportaba un estudio minucioso de los movimientos internos tanto de los médicos como de los enfermos, tanto de los vigilantes como de los sirvientes, tanto de los suministros como de los desechos ${ }^{31}$. Así pues, el hospital se había convertido en una máquina en la cual todas las actividades estaban reguladas, todos los ocupantes registrados, clasificados y distribuidos según su dolencia, todos los movimientos calculados y optimizados. El nuevo modelo de establecimiento no debía basarse ni en la caridad cristiana ni en la voluntad de esconder la miseria, las reglas las dictaba ahora la ciencia médica y su aplicación se fundaba en las necesidades reales debidamente cuantificadas.

\section{Del hOSPITAL AL LAZARETO. LA GÉNESIS DE UN MODELO.}

Al mismo tiempo que se desarrollaba la encuesta que acabaría con el modelado del hospital pabellonario, las ideas inherentes a esta tipología inspiraron los nuevos lazaretos que se estaban erigiendo por aquel entonces en algunos lugares de Europa. Si bien es cierto que las formas surgidas de este debate influyeron en el diseño de los proyectos surgidos a partir de entonces, también lo es que el modelo que inspiraría la disposición final de muchas de los lazaretos pabellonarios ya se encontraba en funcionamiento desde el último tercio del siglo XVII, se trataba del lazareto de Marsella, conocido también como las Nouvelles Infirmeries.

\footnotetext{
30 LASSONE (1788c), p. 37-39.

31 TENON (1788), p. 388-391.
} 
Como muchos hospitales de la Era Moderna, las Nouvelles Infirmeries, eran un complejo que se había construido en varias fases, a base de aditamentos y sin seguir un plan general preestablecido. De la primera etapa (16631683) datan los departamentos limpio y sucio (Grand y Petit Enclos respectivamente) y la administración. En una segunda fase (1729-1733) se añadió el Enclos Saint-Nazare, destinado a patente sucia. Más adelante, entre 1754 y 1759, se erigieron en este nuevo departamento algunos tinglados, y hacia 1785 el lazareto volvió a sufrir modificaciones, entre las que destacan la construcción de nuevos edificios en el interior del nuevo perímetro, la división de los recintos destinados a recibir los enfermos y la disposición de los circuitos de circulación en su interior ${ }^{32}$. Para este texto interesa, obviamente, el estado de las Infirmeries en este último estadio, puesto que además de presentar su configuración cuasi definitiva, la fecha coincide con la del debate en torno al Hôtel-Dieu.

Los cambios sufridos a lo largo de su existencia respondían, lógicamente, a la voluntad de adaptar el establecimiento a las cambiantes necesidades de aislamiento que imponían las garras del devenir. Marsella era el puerto más importante del Mediterráneo francés, tenía el monopolio sanitario y comercial $^{33}$ de las arribadas del Levante y la Berbería ${ }^{34}$ y actuaba como centro redistribuidor de mercancías a otros países ${ }^{35}$. Esta causa explica el constante peligro que las instalaciones cuarentenarias marsellesas corrían de resultar insuficientes y sus sucesivos cambios de ubicación, ampliaciones y mejoras. Las Nouvelles Infirmeries se habían ido adaptando a los nuevos tiempos y, por ello, seguían siendo una instalación moderna y un modelo válido en el que podían inspirarse los otros lazaretos. De hecho, el lazareto de Marsella era un referente no solamente en Francia sino también en el resto de Europa, a pesar de los problemas que pudiese haber ${ }^{36}$ en un establecimiento de estas características.

32 Hildesheimer, F. (1980), Le Bureau de la Santé de Marseille sous l'Ancien Régime. Le renfermement de la contagion. Marsella: Fédération Historique de Provence, p. 60-61.

33 Concedidos por la corono a través de los ârrets de 10 de enero de 1622 y de 23 de enero de 1668 respectivamente.

34 Áreas perennemente sospechosas de sufrir la peste a causa, entre otros motivos, de no desarrollar un política sanitaria.

35 España, por ejemplo, utilizaba, entre otras, las instalaciones de Marsella para el comercio con los infieles, puesto que, por motivos religiosos, estaba en guerra con ellos.

36 Da cuenta de algunos de de ellos HILDESHEIMER (1980), p. 61-75. 


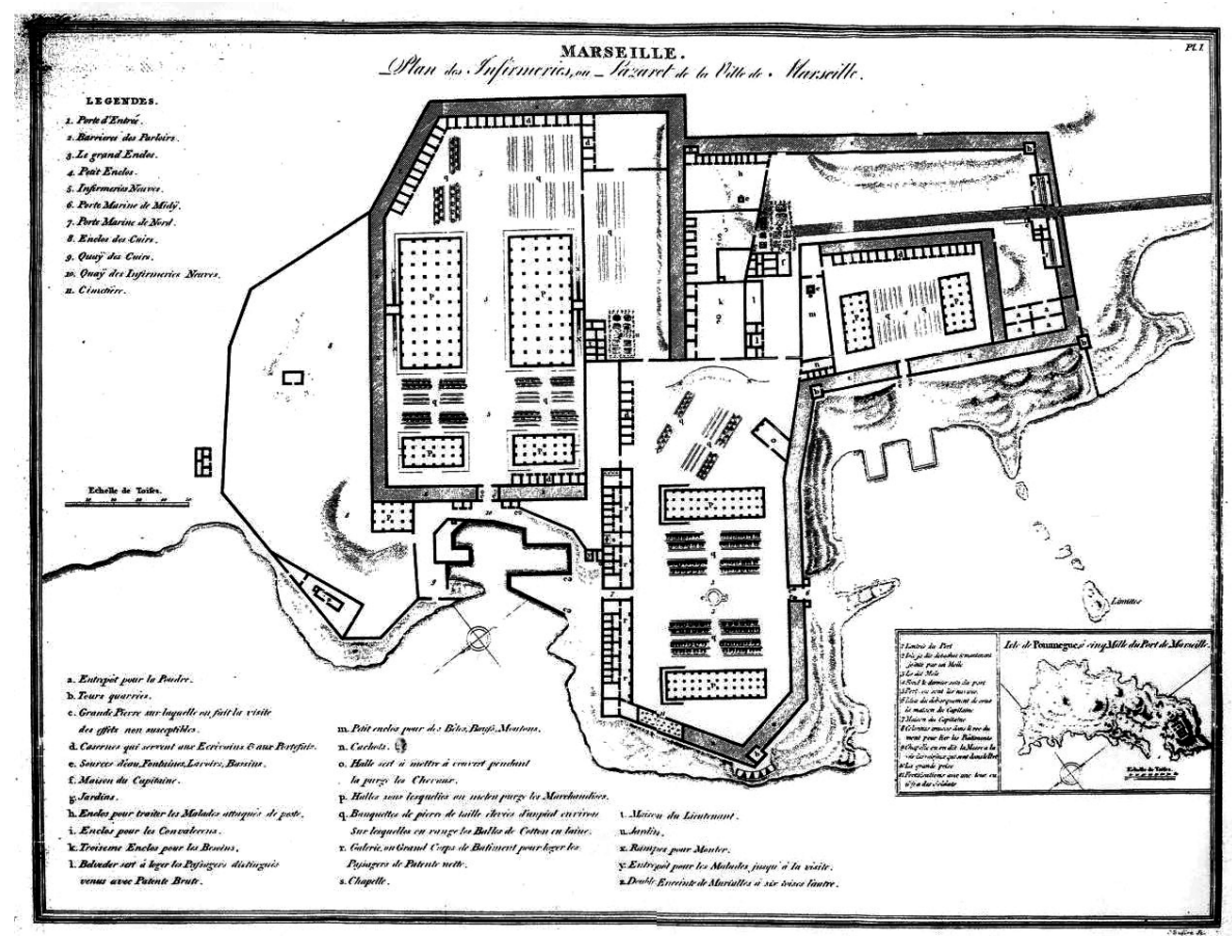

FigurA 5. Plan des Infirmeries ou Lazaret de la Ville de Marseille, por John Howard.

Fuente: HOWARD (1791), plancha 1.

En resumen, el lazareto de Marsella era, en 1785, un complejo de cuarentena en el cual existía una compartimentación bastante estricta de los diferentes departamentos. Contaba con un departamento de patente sucia y con dos para la limpia debidamente separados por una doble línea de murallas, tenía además recintos separados para los enfermos de peste y para los convalecientes y un recinto especial para los cueros, considerados extremadamente peligrosos. Además, poseía diferentes surgideros diferenciados para uso de cada uno de los departamentos y distintos atracaderos en las islas del Frioul, situadas en la rada de Marsella, que asistían en esta necesidad de separación. Esta segregación la encontramos bastante desarrollada en el interior de cada uno de los recintos. Tinglados y banquetas para el expurgo de mercancías se nos presentan multiplicados para atender de manera separada los diferentes lotes 
de mercancías, y los pasajeros, tripulantes, porteadores y escribanos contaban con habitaciones apartadas en el interior de cada separación. Además, las últimas modificaciones en la infraestructura habían mejorado sus flujos de circulación interior, que se realizaban a partir de entonces entre las murallas, cosa que confería mayor seguridad a los desplazamientos en el seno del lazareto. Salvando las distancias, puesto que no se trataba de un establecimiento erigido ex novo y que su configuración no era el fruto de un largo proceso de investigación sino de adaptación a las exigencias de las nuevas coyunturas, se puede afirmar que, de algún modo, el lazareto marsellés comulgaba con las ideas surgidas del debate sobre los hospitales que se estaba desarrollando en aquel entonces en Francia. Por ello, no tiene que resultar extraño que sirviese de modelo para los lazaretos que, en adelante, se construyeran siguiendo los postulados establecidos por la Académie des Sciences francesa.

\section{El lazareto de John Howard}

John Howard, el filántropo inglés al que debemos un estudio pormenorizado de las prisiones, los correccionales, los hospitales y los lazaretos de casi todos los países de Europa, publicó en su informe sobre estos últimos un proyecto de lazareto modelo para su país. De hecho, dejó solamente un plano y unas mínimas apreciaciones que, en definitiva, ya eran bastante sintomáticas de la idea que creemos que Howard tenía sobre el asunto.

Conocedor de los establecimientos carcelarios y de los lazaretos, consideraba que los segundos tenían demasiado el aspecto de los primeros, en este sentido explicaba:

I have often heard captains in the Levant trade say, that the spirits of their passengers sink at the prospect of being confined in them. In those of them which I have visited, I have observed several pale and dejected persons, and many fresh graves. To prevent as much as possible this disagreeable circumstances, a lazaretto should have the most cheerful aspect. A spacious and pleasant garden in particular, would be convenient as well as salutary ${ }^{37}$.

Estas líneas son, de hecho, el único comentario que acompaña a la plancha en la que presenta la planta de su modelo, por lo que, para reconstruir la idea

37 Howard, J. (1791), An Account of the Principal Lazarettos in Europe, with Various Papers Relative to the Plague and Additional Remarks on the Present State of Prisons in Great Britain and Ireland. 2nd ed. London: Johnson, Dilly and Cadell, p. 23. 
que el británico tenía sobre como debían ser estos establecimientos, debemos acudir a la descripción que hizo de los que visitó durante su viaje por Europa y desgranar su discurso entre los comentarios que, tanto en positivo como en negativo, hizo de ellos ${ }^{38}$.

Así, aparte de abogar por un lazareto alegre y alejado de la estética de la cárcel - cosa que explica la introducción de zonas ajardinadas tanto en el interior como en derredor de su establecimiento- Howard denota en sus comentarios una preferencia por los espacios amplios, compartimentados y bien aireados. Esta opinión está relacionada con el concepto de transmisión que manejaba el inglés, modelado por sus amigos los médicos John Aikin y John Jebb. La peste no se comunicaba por contacto sino que habitualmente el contagio llegaba por inoculación o por la respiración de los efluvios pútridos que, en suspensión, envolvían los objetos infectados. Estas emisiones podían ser transportados «in the same manner that the smell of tobacco is carried from one place to another ${ }^{39}$, aunque nunca a grandes distancias. En estrecha relación con esta concepción, el filántropo otorgaba una gran importancia a la limpieza del recinto en general y de los apartamentos en concreto, se debía evitar a toda costa la suciedad y la humedad, capaces de engendrar miasmas, y era muy importante dotar de agua fresca a todas las partes del complejo, hecho que redundaría en su limpieza y salubridad.

Estas ideas explican la disposición del esbozo que acompaña su texto. Un plano que, aunque no concuerde en algunos aspectos con el de otros lazaretos de tipo pabellonario que se construirían en el resto de Europa, comparte los líneas generales del modelo que en esa época se estaba gestando. De hecho, las diferencias con éste obedecen más a una cuestión de sensibilidad e ideario de índole estética producida por sus referentes culturales que a razones científicas ${ }^{40}$. De este modo, Howard nos ofrece un proyecto de estación cuarentenaria en el están implícitas cada una de las nociones básicas de los establecimientos pabellonarios. En el plano se puede ver un gran espacio abierto situado

\footnotetext{
38 HOWARD (1791), p. 3-23.

39 HOWARD (1791), p. 24.

40 Me refiero, sobre todo, a la introducción de la naturaleza en el seno del lazareto y a la menor compartimentación física en el interior de cada uno de sus departamentos, que tenían que acentuar la percepción del establecimiento como un jardín. De este modo, el medio natural, ofrecería las mayores ventajas tanto para la salud física como moral de los secuestrados. Analizo esta idea en relación con los lazaretos en BonASTRA, Q. (2007), «Romanticismo y naturaleza en la prevención de las epidemias en América del Norte. El modelo paisajista de lazareto y su implantación en Canadá». Geo-Crítica / Scripta Nova, 11 (250), 15 de octubre de 2007. En línea [http://www.ub.es/geocrit/sn/sn-250.htm]
} 


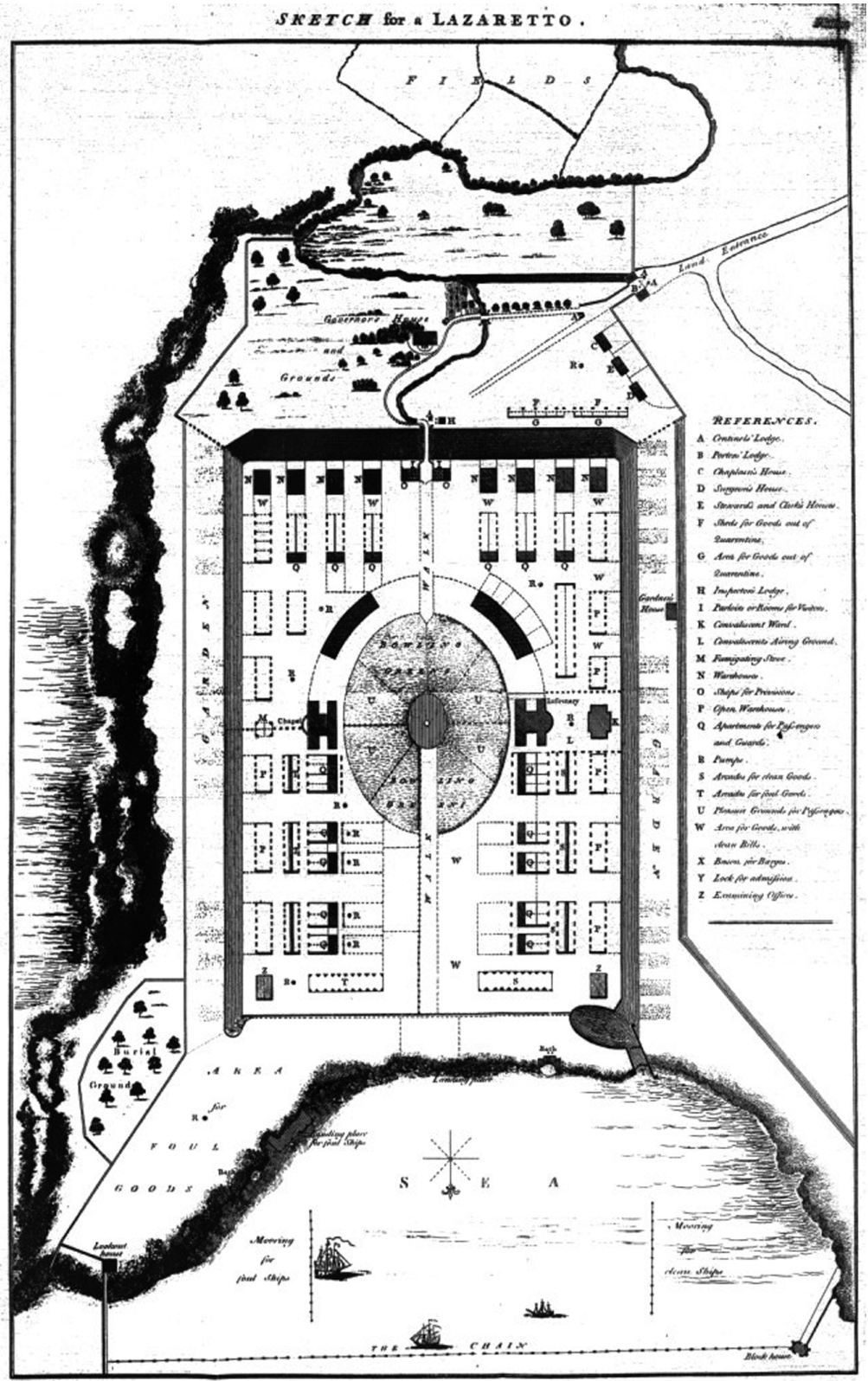

FIGURA 6. Sketch for a Lazaretto, por John Howard. Fuente: HOWARD (1791), plancha 14. 
a la orilla del mar y constantemente bañado por el aire. En su interior están perfectamente delimitadas y segregadas las áreas que debían dar servicio a las embarcaciones de patente limpia y sucia; los apartamentos para cuarentenistas y guardias, los almacenes y galerías - abiertos para permitir el aireo de las mercancías - y los tinglados cerrados se encuentran multiplicados y dispuestos de manera seriada, de modo que pudieran asegurar una perfecta separación e incomunicación, tanto de los diferentes grupos de secuestrados como de las partidas de mercancías. Así, para cada barco se ubicaban apartamentos y una parte del terreno de solaz para la tripulación, así como almacenes y galerías abiertos para airear su carga. Por otra parte algunos servicios - entre otros las fuentes ${ }^{41}$, la capilla, la enfermería o la sala de convalecientes- serían comunes para todo el conjunto.

Como se ha visto, el plan de lazareto de Howard para Inglaterra concordaba bastante con las ideas que se encontraban detrás de la reforma hospitalaria iniciada en Francia a finales del setecientos. En su proyecto se intuye la necesidad del mantenimiento de un aire puro en el interior del recinto y de una estricta y reiterada separación de las personas y los géneros alojados en su seno, pero lo que no queda tan claro es la importancia concedida a los flujos de circulación internos. Si bien en su explicación omite estos detalles, también es verdad que el canal de circunvalación que rodea el campo cuarentenario podía, del mismo modo que lo hiciera el pasillo cubierto del proyecto de hospital de Tenon, hacer las veces de vía tránsito, tanto de personas como de mercancías, desde su lugar de expurgo hasta el exterior. De todos modos, los lazaretos que se construyeron en otros países de Europa, sobre todo en España y en Francia, siguieron una configuración un tanto distinta, bastante apartada de esta necesidad de alegría paisajista que, en cierto modo, pregonaba Howard.

\section{El lazareto de Mahón}

Durante el setecientos, tal y como había ocurrido en Francia, el modelo asistencial vigente en España fue puesto en entredicho. A lo largo del siglo se fue afianzando la opinión de que el hospital debía segregarse del hospicio, dejar de ser el depósito de la pobreza y de la miseria ${ }^{42}$. Este estado de opinión se reforzó durante el último tercio de siglo a causa de la difusión de las ideas de Howard y

41 En la patente sucia cada uno de los subconjuntos cuarentenarios disponía de una fuente propia. Ver el plano del lazareto.

42 Da cuenta de ello GRANJEL, L. S. (1979), La medicina española en el siglo XVIII. Salamanca Universidad de Salamanca, p. 125-130. 
de las de la Academia francesa sobre los hospitales ${ }^{43}$. En este contexto, en 1787 y por inspiración de Floridablanca, Carlos III promulgó la Real Orden de 14 de septiembre por la cual se ordenaba construir un lazareto en la península de Felipet, a la entrada del puerto de Mahón ${ }^{44}$. Lógicamente, esta actuación era uno de los corolarios de la política sanitaria impulsada por los borbones, que sentó las bases de una gestión de la sanidad centralizada y jerarquizada y que tenía entre sus ocupaciones principales el resguardo contra las epidemias ${ }^{45}$.

La idea era construir un «Lazareto que sea capaz de cumplir con una concurrencia de Comercio como puede tener toda la España de todo el Mediterraneo á Levante de si misma y que haia de servir á las Quarentenas de toda especie de Patente en disposición que de el, salgan purificadas todas las Embarcaciones para la Peninsula» ${ }^{46}$. Este propósito, lejos de constituir un plan aislado, formaba parte de un proyecto más amplio que tenía que arreglar los problemas de España siguiendo las directrices del despotismo ilustrado, para lo cual se requería, entre otras cosas, promover la riqueza de la nación y obtener la felicidad de los súbditos. De este modo el lazareto de Mahón sería concebido como una ciudad-servicio ${ }^{47}$ integrada en un territorio articulado y

43 Según Sambricio, las ideas de Howard y las de la Academia Francesa respecto a los hospitales eran conocidas por los diferentes ingenieros que participaron en el proyecto de Mahón. Traza el recorrido de la difusión de estas ideas en SAMBRICIO, C. (1991), Territorio y ciudad en la España de la Ilustración. Madrid: Mopt, p. 419-421. En otro texto de Sambricio se puede ver como ciertos grupos de ilustrados españoles mantenían un estrecho contacto con las ideas que se estaban gestando en Francia. Ver SAMBRICIO, C. (1986), La arquitectura española de la ilustración. Madrid, Consejo Superior de los Colegios de Arquitectos de España y Instituto de Estudios de la Administración Local, p. 423,

44 Explico los intentos de construir una red de resguardo sanitario en España durante el setecientos, la elección de Mahón como lugar en el que instalar el lazareto general de España y las razones que motivaron esta decisión en BonASTRA, Q. (2008), «El largo camino hacia Mahón. La creación de la red cuarentenaria española en el siglo XVIII». En LÓPEZ MORA, F. (Ed.), Modernidad, ciudadanía, desviaciones y desigualdades. Córdoba: Universidad de Córdoba (en prensa).

45 Ver al respecto VArela Peris, F. (1998), «El papel de la Junta Suprema de Sanidad en la política sanitaria española del siglo XVIII». Dynamis, vol. XVIII, p. 315-340; y RoDRÍGUEZ OCAÑA, E. (1987-88), «El resguardo de la salud. Organización sanitaria española en el siglo XVIII. Dynamis, vol. VII-VIII, p. 145-170.

46 Fernandez de Angulo, F. (1786), Ydea del proyecto de un Lazareto general de Cuarentena en el Puerto de Mahon Ysla de Menorca... S.H.M., exp. 12.892, sig. 3-3-1-5.

47 SAmBricio (1991), p. 418. Sobre el concepto de ciudad-servicio ver TEYsSOT, G. (1977), «Città-servizi. La produzione dei Batiments Civils in Francia (1795-1848)». Casabella, 424, p. 56-64. 
complementario que se promovía desde la Corona ${ }^{48}$, y no como una función más de una urbe concreta. En este sentido es importante la elección de Marsella como modelo a seguir puesto que, como ya se ha dicho, su lazareto cumplía el mismo cometido para las costas francesas del Mediterráneo.

Pero la cuarentena de Marsella era también un referente en cuanto a su configuración, sobre todo por su capacidad de acoger los barcos de manera separada en los surgideros del Frioul, antes de transportar los géneros al lazareto. Esto se podía conseguir en Mahón, aunque de manera no tan perfecta, gracias a la colocación de la cuarentena en la península de Felipet. De este modo la cala Taulera, situada al este del complejo, haría las veces de fondeadero para la patente sucia y la zona comprendida al oeste del lazareto podría acoger separadamente las embarcaciones de patente limpia y sospechosa.

El ingeniero Fernández de Angulo, a quien debemos el diseño del proyecto, optaba, siguiendo los principios que se estaban gestando en Francia en esa época, por una solución de hospital en pabellones, aunque pasada por el tamiz del modelo que ofrecía el establecimiento marsellés. Leamos sus propias palabras:

«Deve primeramente coger mucha extensión de terreno. Debe estar circuído de dos paredes muy altas (lo menos de 9 varas y $1 / 2$ ) paralelas, que hacen una doble cerca que dexa un bacio, ó camino en medio de 14 á 15 varas, para que nada se pueda tirar de dentro á fuera, y para otras precauciones. (...)

Debe despues tener divisiones de paredes interiores, dobles y sencillas, que formen encierros diferentes, para las varias clases de Patentes, y en cada una Almacenes grandes, Alojamientos comodos y Hopitales. Deve haver tambien, un encierro particular para contagiados, y terrenos donde estender pieles, algodones, hacer serenas, y de todo mucho; pues que puede haver Buque que necesite descargar todo para purificarse ó para componer sus averías ó también ser Navios de la Rl. Armada. $)^{49}$

Además se preveían toda una serie de equipamientos (hospitales, enfermerías, fonda, alojamientos...) en su interior y una serie de encierros separados para los diferentes tipos de tripulantes, atendiendo a la patente con la cual viajaban y a su estatus social. Por otro lado se tenía en cuenta la correcta aireación de cada uno de los edificios, ya fueran los almacenes de mercancías, los albergues para cuarentenistas o los de servicio, ofreciendo soluciones concretas y evitando situarlos adosados a los muros.

48 Habla de ello Reguera, A. (1993), Territorio ordenado, territorio dominado. Espacio, políticas y conflictos en la España de la Ilustración. León: Universidad de León.

49 FERnANDEZ de ANGULO, F. (1786) 


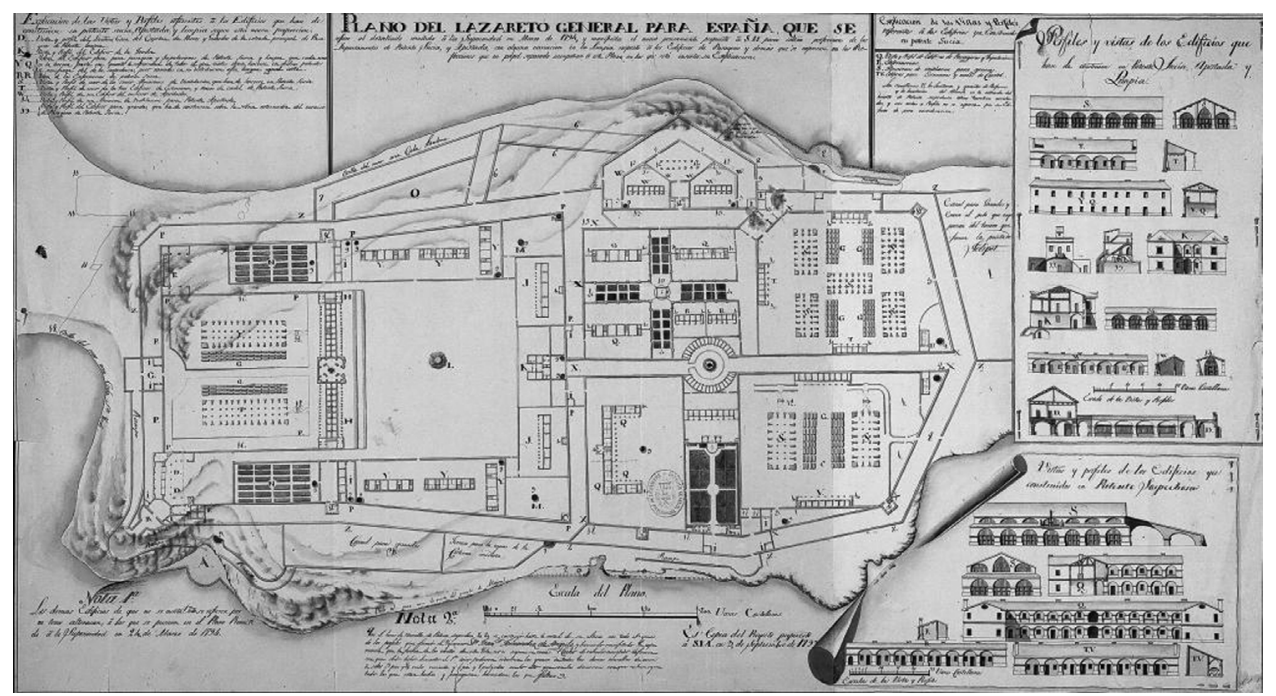

FiguRA 7. Plano del Lazareto General para España ..., proyecto de 3 de septiembre de 1794.

Fuente: Servicio Histórico Militar, 3588-17.

El proyecto inicial, a medida que se iba construyendo ${ }^{50}$, sufrió, manteniéndose fiel al esquema original, unas cuantas mejoras tendentes a perfeccionar y a aumentar la separación interior de las diferentes partes del lazareto para evitar contagios. Así, se multiplicaron los cercados en el interior de los departamentos, también los almacenes —en los que se podría distribuir los géneros de manera más lógica y con menos peligro para los mozos de cordel- y los edificios de acogida de pasajeros — que podrían ser acogidos de manera más separada y atendiendo a las distintas temporalidades marcadas por la patente sanitaria de cada barco- - Del mismo modo, se prestó una mayor atención a las corrientes de aire que debían bañar el recinto y que debían asegurar una constante purificación de las instalaciones. En definitiva, a medida que se iban perfilando los detalles del proyecto, se acentuó en él su carácter pabellonario. Su departamento de patente sucia, por ejemplo, estaba, según Manuel Rodríguez Villalpando, distribuida «con tal inteligencia, que pueden avitar en ella, sin roce, las diversas

50 No me detendré en detallar todos los cambios que sufrió el proyecto hasta la inauguración del lazareto, expone una prolija bibliografía sobre este particular: SAMBRICIO (1991), p. 428-429. 
tripulaciones, que vayan entrando, y se allen en distintas épocas de cuarentena y espurgo. ¡Ventaja de alta consideración en un lazareto general!»» ${ }^{51}$.

El lazareto de Mahón fue el primer exponente de lazareto pabellonario, surgido al mismo tiempo que tenía lugar el debate sobre los hospitales en Francia, y bebiendo directamente de sus fuentes y del referente marsellés. Su importancia, sin embargo, fue obviada por los tratadistas que, a los pocos años, sentarían las bases teóricas del modelo vigente hasta entrado el siglo XX.

\section{LA CONSOLIDACIÓN DEL MODELO. LOS LAZARETOS PABELLONARIOS FRANCESES}

Consolidado el modelo de hospital en pabellones, avanzados los primeros intentos de traspasar estas ideas a la construcción de lazaretos ${ }^{52}$, vieron la luz en Francia dos proyectos que intentaban fijar las bases del nuevo tipo de establecimiento cuarentenario. El acicate para su modelado era totalmente nuevo, la toma de conciencia del peligro que representaba la fiebre amarilla, pero en su esencia las formas resultantes serían las mismas, como también eran los mismos los modelos en que se inspiraban. Como ya se ha dicho, el gran olvidado en esta función fue el lazareto de Mahón, obviado acaso por tratarse del buque insignia de una potencia enemiga la cual, presa de los desmanes liberales, no había sabido evitar que el vómito negro se enseñoreara de su territorio. En cualquier caso, parece que de los mismos polvos resultaron unos lodos casi idénticos y el modelo pabellonario de lazareto echó unas raíces fuertes y profundas en Francia, donde se consolidó y difundió la nueva tipología cuarentenaria.

\section{El modelo de Bruyère}

Durante la segunda fase de conquista napoleónica, perteneciendo el norte de Italia al Imperio, los ingenieros franceses Bruyère y Rolland fueron enviados a la zona de la desembocadura del Po. Tenían la misión de estudiar el

51 Rodríguez, M. (1813), Lazareto de Maón ó Memoria descriptiva de sus obras, reflexiones críticas sobre su estado actual y proyecto para que sea general y puerto franco en beneficio del comercio del Mediterráneo. Mahon: Imp. de Pedro Antonio Serra, p. 14. A través de este texto se puede conocer el estado del lazareto en 1813, cuatro años antes de su apertura definitiva.

52 El lazareto de Mahón entraría en pleno funcionamiento como lugar de cuarentena a partir de 1817. 
curso de este río hasta el mar, examinar la rada de Goro y visitar los diferentes puertos del Adriático entre Goro y Cattolica. La finalidad última consistía en la redacción de una memoria sobre su estado y sobre las mejoras de que eran susceptibles, así como la de recomendar la construcción de nuevos puertos en caso de que esto se juzgara necesario ${ }^{53}$. Esta memoria, redactada en 1805 a su regreso a París, vio la luz años más tarde, impresa en una colección de estudios sobre arquitectura, ordenada en forma de ensayos temáticos ${ }^{54}$. A su vuelta de la misión Bruyère y Rolland propusieron la fundación de una ciudad cerca de la de Comacchio que tenía que convertirse en puerto comercial para el tráfico de Levante y estar abierto a los intercambios con todas la naciones. Su situación estratégica para el Imperio obligaba a emplazar en el nuevo puerto un lazareto que, por la importancia del proyecto, debía fundarse sobre las bases más estrictas de la eficiencia ${ }^{55}$ para la prevención contra la peste ${ }^{56}$.

El estudio detallado de los planos de los lazaretos del Mediterráneo pertenecientes entonces al Imperio (Marsella, Génova, La Spezia, Liorna y Anco-

53 Esta prospección formaba parte de un proyecto más amplio entre cuyos fines se encontraba la unión del Adriático y el Tirreno mediante una vía navegable. Sobre el proyecto general ver MORACHIELLO, P. «Il prefetto Chabrol. Amministrazione napoleonica e 'scienza dell'ingegnere'». En Morachiello, P y TEyssot, G. (Eds.), Le macchine imperfette. Architettura, programma, istituzioni, nel XIX secolo. Roma: Officina Editori, p. 146-188.

54 BRUYÈrE, L. (1828), «Esquisse d'une petite ville maritime et Essai sur les lazarets. Xe Recueil». En BRUYĖRE, L. Études relatives à l'art des constructions, recueillies par... Paris: chez Bance ainé, vol II. No he podido establecer la fecha exacta de la primera concepción del proyecto al no haber podido acceder a todos los documentos relacionados con éste. Se deduce, sin embargo, que Bruyère visitó el lazareto de Génova en 1805 y que obtuvo la información sobre el lazareto de Marsella durante la época en que M. Desfougères, amigo suyo, era el inspector. Todo parece indicar que su programa es anterior a 1822, fecha del informe de la Comisión Sanitaria Central.

55 Morachiello, P. (1978), «Bruyère, Comacchio e il «programma» dei Lazzaretti in Italia (1805-1823)». Casabella, 439, p. 52-59, p. 52.

56 El matiz es importante puesto que, cuando el ensayo fue impreso en 1828, Bruyère afirma haber conocido a última hora el proyecto de 1822 de la Comisión Sanitaria Central para construir lazaretos contra la fiebre amarilla, que será tratado en el apartado siguiente. Bruyère, a la vista de las diferencias en la propagación de ambas enfermedades - aceptando que el vómito negro era transportable a más distancia que la peste y estaba más sujeto a las variables ambientales y prefiriendo para su desarrollo los lugares húmedos y calurosos y que la peste casi nunca se comunicaba sin contacto - tiene cuidado de afirmar que sus lazaretos servirían para la prevención de la peste aunque, como se verá más adelante, las diferencias morfológicas de ambos proyectos eran casi nulas y el acento se ponía en el emplazamiento del complejo y en la orientación y separación de los edificios. 
na) - estudio que se haría teniendo en cuenta razones científicas y desestimando cualquier supuesto estético ${ }^{57}$ - daba preeminencia a la configuración del establecimiento provenzal, del cual se hacía una pormenorizada descripción en el ensayo.

En términos generales se puede afirmar que la disposición resultante no difería excesivamente del lazareto de Mahón, aunque en su programa se resaltaba de una manera más pronunciada los principios que regían el modelo. La atención se extremaba en la separación de los cuarentenistas y las mercancías - que se conseguiría gracias a la multiplicación de unidades aisladas por muros atendiendo a los diferentes periodos de cuarentena ${ }^{58}$ - , en la aireación del recinto y de sus edificios - dada por el emplazamiento del conjunto en un lugar algo elevado y bañado por el viento, por su amplitud y por la descomposición en módulos separados por muros y por pasillos de comunicación-, y en los flujos en el interior del complejo - asegurados por los pasillos colocados entre los diferentes recintos y que debían unir todas las unidades del complejo, cuyos servicios comunes debían ocupar una posición central que permitiese tanto la facilidad de las operaciones como la vigilancia. Vigilancia que se conseguiría también a base de guardias en cada uno de los encierros-.

En su programa, Bruyère fijó de forma casi definitiva el modelo de lazareto pabellonario, lo que se hace aún más patente si tenemos en cuenta que presentaba tres planos diferentes en los cuales, siguiendo los mismos principios, ofrecía distintas soluciones morfológicas dependiendo de la naturaleza de terreno en el cual se debía emplazar el lazareto. Además contemplaba la variación de las dimensiones de los recintos teniendo en cuenta la posición ocupada por el establecimiento en la jerarquía urbana y el volumen de su comercio.

57 El lazareto de Ancona, por ejemplo, era considerado poco apropiado para su cometido: «Cette disposition, plus architecturale que convenible, ne satisfait pas aux conditions essentielles. L'élévation des bâtiments, leur continuité, et le peu d'étendue de la cour, s'opposent au renouvellement de l'air; aucun service n'est isolé, les quarentenaires sont placés trop près des marchandises et sous le même toit...». BRUYÈRE (1828), p. 17.

58 «L'emplacement du lazaret (dont l'étendue se détermine para celle du commerce) doit être circonscrit par une clôture générale de 4 à 5 mètres de hauteur, distans entre eux de 10 à 12 mètres, et séparés des propriétés particulières par un chemin de ronde extérieur. L'espace total compris dans la clôture générale doit être divisé en un certain nombre de parties closes par d'autres murs, isolées les uns des autres par des chemins de communication. Le nombre et l'étendue de ces enclos particuliers varieront suivant l'importance de l'établissement». BRUYÈRE (1828), p. 17-18. 


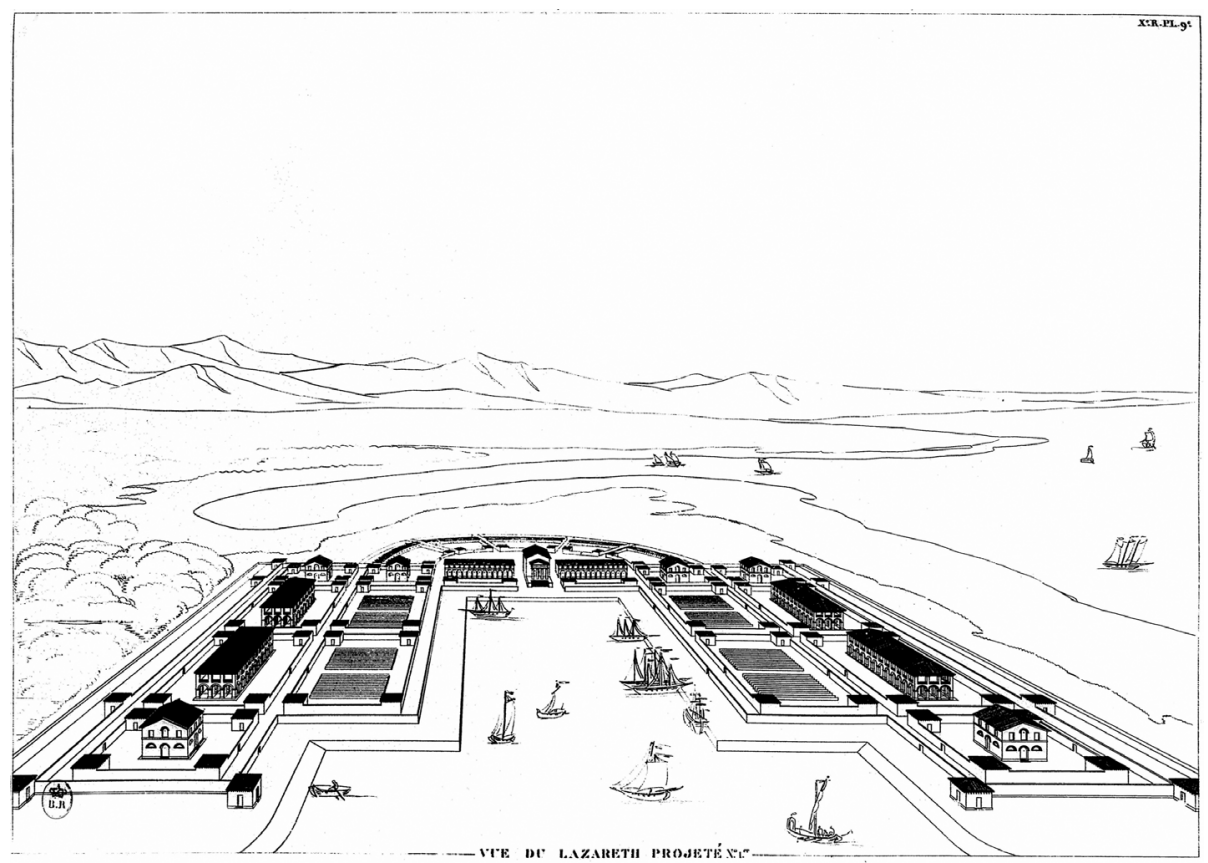

FIGURA 8. Vue du Lazareth projeté $N^{o} 1$, por Louis Bruyère.

Fuente: BRUYÈRE (1828), plancha 9.

\section{La irrupción de la fiebre amarilla y el informe Hély d'Oissel}

Se debe relacionar el afianzamiento definitivo del modelo pabellonario de lazaretos con la epidemia de fiebre amarilla que sufrió Cataluña en 1821. Aparte de las medidas punitivas tomadas en Francia contra el gobierno liberal español, a través del cierre de las comunicaciones y la imposición de un cordón sanitario-político en los Pirineos, este brote epidémico hizo que el gobierno francés planteara la reforma de su política profiláctica y, sobre todo, de sus lazaretos. Para ello se creó una comisión a instancias del Ministerio del Interior cuyo cometido era presentar un plan de lazaretos para todo el país, que debía proponer tanto una tipología adecuada, como los lugares concretos de los emplazamientos en el Mediterráneo y en el Atlántico ${ }^{59}$. Dicha comisión

59 De la que resultó el siguiente informe: HÉLy D’OISSEL, A.-P. (1822). Rapport sur l'établissement de nouveaux lazarets, adopté par la commission sanitaire formée près le mi- 
estaba presidida por un filántropo, el baron Joseph-Marie de Gérando, y estaba formada por Abdon-Patrocle Hély d'Oissel, consejero de estado; por Pierre-François Keraudren - que era médico e inspector general del servicio de salud de la marina - ; por el economista Alexandre Moreau de Jonnès y por el intendente de sanidad de Marsella, Majastre ${ }^{60}$.

Debemos tener en cuenta que sus autores creían que el vómito negro era altamente contagioso, puesto que, según ellos, además de contagiarse por contacto mediato e inmediato, como suponían que ocurría con la peste, se transmitía también por el aire con el concurso de el calor y la humedad, tanto en espacios cerrados como a una cierta distancia, siempre que no se excediera los veinticinco pies ${ }^{61}$. Este hecho determinaba tanto el emplazamiento de los lazaretos, para el cual eran mejores los lugares algo aislados, elevados, secos y batidos por los vientos dominantes del lugar, como su orientación, barrido por los vientos dominantes por la diagonal del recinto, que debía ser cuadrado, y con la puerta principal a sotavento.

La comisión conocía la disposición de varios lazaretos: el de Marsella, el de la Spezzia, los tres de Liorna, el de Messina, el de Ancona, el de Venecia y el de Trieste, a los que había que sumar el proyecto de los lazaretos de la Pointe du Hoc, en la desembocadura del Sena, y del de Saint Nazaire, en la del Loira. Pero ninguno de los planos satisfizo a la comisión, ni en la distribución, ni en la organización, puesto que consideraba que ninguno de ellos podía ser tomado, ni en su conjunto, ni en sus detalles, como modelo. Sus principales defectos eran: la aglomeración de sus edificios, la peligrosa cercanía de los almacenes y de los alojamientos de los internos y la falta de previsión para asegurar la renovación del aire.

El mejor lazareto para la fiebre amarilla sería, para los miembros de la comisión, «celui qui offrirait l'enceinte la plus spacieuse, et le plus possible de divisions et d'isolement dans les bâtiments destinés à recevoir les personnes qui devraient y faire quarantaine $\left.{ }^{62}\right\rangle$, afirmación respaldada por el ejemplo parisino ${ }^{63}$. El éxito de las operaciones sería mayor si «des cou-

nistère de l'Intérieur. Paris: Imprimerie Royale. Agradezco a Pierre-Louis Laget el envío de una copia de este informe.

60 LAGET, P.-L. (2002). «Les lazarets et l'émergence de nouvelles maladies pestilentielles au XIXe et au début du XXe siècle». InSitu: la revue de l'Inventaire, 2, p. 1-11.

En línea [http://www.culture.gouv.fr/culture/revue-inv/002/pll002.pdf]

61 HÉLY D'OISSEL (1822), p. 8-9.

62 HÉLy D'OISSEL (1822), p. 12.

63 Donde ya se habían empezado a aplicar en la práctica las ideas surgidas en el debate sobre los hospitales y en los cuales «il a suffi de s'attacher à diminuer la population de chaque 
rans d'air sagement ménagés renouvellent dans la masse de l'atmosphère générale» ${ }^{64}$.

Los autores de la memoria proponían distintos planos de lazareto de 100, 150, 200 y 300 metros de lado que, en esencia, eran casi idénticos al de Mahón o a los de Bruyère. Los dos últimos, por su extensión, podrían emplazarse en cualquiera de los puertos más importantes de Francia; los otros servirían para los de menor importancia. La forma de la planta de los lazaretos tenía que adaptarse, en la medida de lo posible, al cuadrado. Esta geometría era la que permitía, después de la planta circular, un mayor aprovechamiento del espacio con menos gasto y desarrollo de muros. Otra razón para adoptar esta forma era la posibilidad de vigilar mejor con un menor número de guardianes colocados en garitas dispuestas en cada una de las esquinas, algo que no permitía una planta redonda ${ }^{65}$. Está claro que este control se ejercía desde fuera hacia dentro. Para el aislamiento del exterior consideraban necesario que el recinto contara con un cinturón de ronda de una amplitud de veinte metros ${ }^{66}$, con muros hacia fuera y hacia dentro del lazareto.

El proyecto presentado por la Comisión Sanitaria Central, dibujado por los arquitectos Alavoine y Godde, significó el último eslabón en la configuración del modelo de lazareto pabellonario. Modelo que se aplicaría a partir de entonces en Francia y del cual se harían eco otras instalaciones extranjeras. Diseñado para evitar la fiebre amarilla, se prestaba en él una especial atención al mantenimiento de una atmósfera saludable, cosa que daba más amplitud a las instalaciones y marcaba los recorridos por el interior del recinto y la disposición de los distintos encierros y servicios comunes, multiplicados según la importancia del lazareto. La voluntad de crear un modelo aplicable a todos los puertos de Francia hizo que se dibujasen hasta siete planos distintos, de diferentes medidas y ordenación interior. Conviene añadir que existe un punto de unión muy importante entre estos lazaretos con el propuesto por Howard, la importancia prestada al aspecto jovial del conjunto, que se debía conseguir con jardines, arboledas y césped y la atención que se prestaba al asueto de los cuarentenistas.

hôpital, de répartir les malades dans un plus grand nombre de maisons, de ménager dans les salles des moyens de ventilation, de faire fréquemment laver les planchers...». HÉLY D'OISSEL (1822), p. 11.

64 HÉly D'OISSEL (1822), p. 11.

65 HÉLY D’OISSEL (1822), p. 18.

66 Éste, además de camino entre las diferentes unidades aisladas, podía servir, según la comisión, como huerto en el que se cultivarían legumbres y hortalizas siempre que no dificultasen la visión de los vigilantes. 


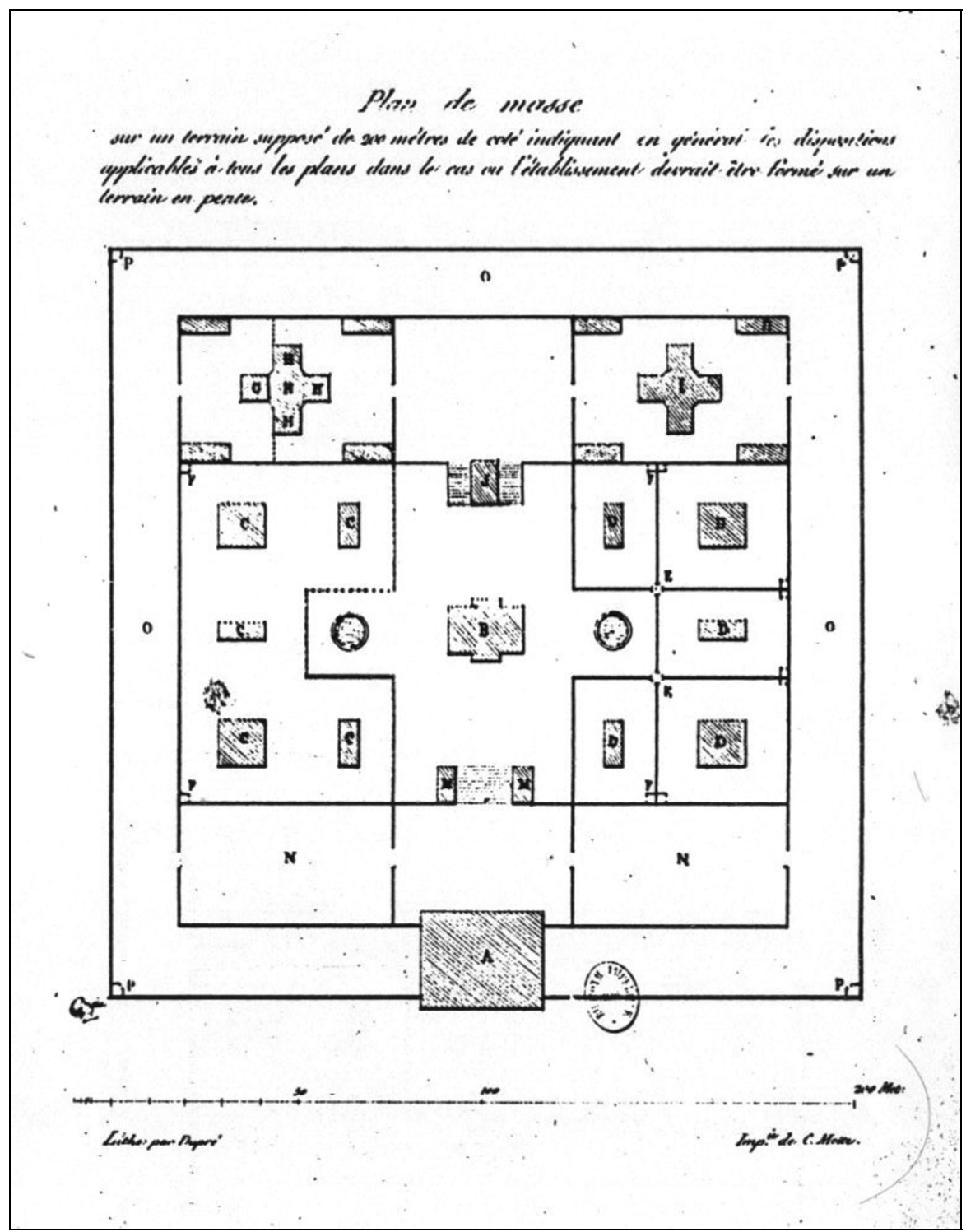

FIGURA 9. Plan de masse sur un terrain supposé de 200 mètres de côté indiquant en général les dispositions applicables à tous les plans dans le cas ou l'établissement devrait être formé sur un terrain en pente, por Alavoin y Godde.

Fuente: HÉly D’oISSEL (1822), plancha 6. 


\section{CONCLUSIONES}

El modelo pabellonario de lazareto adquirió un papel relevante entre las tipologías cuarentenarias en el marco de la reforma hospitalaria acaecida a finales del setecientos. El pensamiento nosológico, tomando el patrón de la botánica, agrupaba las enfermedades por especies. Este paradigma fue la referencia que se siguió a la hora de diseñar nuevas instalaciones asistenciales, lo cual explica el proceso de descentralización y de segregación funcional que apreciamos en ellas. Así, el hospital, desprendiéndose del hospicio, agrupaba a los enfermos según su género y su dolencia. Todo ello se realizaba en el seno de una infraestructura en la cual el trabajo de clasificación exigía una máxima división de los espacios. De este modo se proporcionaba a los enfermos una atención ordenada y efectiva, se evitaba la propagación del contagio y se ayudaba a la conservación de un aire sano en el interior del recinto. El hospital, que debía estar totalmente subordinado a las leyes médicas, fue sometido a un análisis minucioso. Una vez justificada la refutación del antiguo modelo, se cuantificaron sus necesidades, se segregaron funcionalmente sus espacios, se regularon sus flujos interiores, se previó su abastecimiento y limpieza, etc. Todas estas operaciones se encaminaban a hacer de él una máquina para curar, tal como lo denominaron quienes participaron en su modelado.

De algún modo, estas ideas se encontraban ya implícitas en el diseño de los primeros lazaretos pabellonarios, en los cuales el ejercicio de separación era un principio insoslayable. El nuevo marco teórico aportaba al espacio cuarentenario una mayor eficacia. Las instalaciones fueron sometidas a una estricta reordenación en cuya base se encontraba la compartimentación de los recintos de manera que pudieran albergar a cuantos cuarentenistas y mercancías fuese necesario. Esta separación serviría para impedir que el aire contaminado exhalado por los enfermos o las mercancías pudiera afectar al resto de secuestrados. Cada tripulación debía tener sus apartamentos y cada cargamento su espacio para las serenas; todo ello debía estar bien separado y ordenado en el interior del departamento que les correspondía.

Los movimientos dentro del lazareto se realizarían por los pasillos situados entre los muros de los distintos encierros y también estarían regulados, cosa que permitiría evitar los encuentros no deseados y la consiguiente propagación del contagio. Todas estas operaciones se sucederían bajo la estricta vigilancia del capitán del lazareto y de los numerosos guardias que impedirían el quebrantamiento de las normas de aislamiento.

Queda por determinar si el origen de la idea procede los propios lazaretos o de los hospitales. Está claro que las Nouvelles Infirmeries de Marsella fue- 
ron, en general, la fuente de inspiración para la adopción de soluciones morfológicas para los lazaretos ${ }^{67}$. En este sentido entendemos que aquello que los hospitales prestaron a los lazaretos fue el criterio ideológico fijado por el patrón de la Comisión Sanitaria Central francesa y no tanto el diseño de la planta de un edificio. En el sentido inverso, es importante recordar que, a pesar de que los miembros de la comisión de los hospitales citan como principal fuente de inspiración para el modelado de su hospital al Royal Naval Hospital de Plymouth $^{68}$, también se manejaron los informes de la Académie de Marine sobre barcos, lazaretos y hospitales militares, de lo que se puede presumir que existió una cierta transferencia hacia los hospitales de las ideas subyacentes en el diseño y organización de los lazaretos.

En otro orden de cosas, hay que destacar que la difusión del modelo pabellonario de lazareto fue bastante amplia. Se ha visto, no obstante, que el proyecto presentado por Howard en su memoria sobre los lazaretos, aunque es pabellonario, se apartaba de este tipo de configuración, pero que el lazareto de Mahón y los proyectos franceses que se han analizado, seguían estrictamente este modelo. Los lazaretos que se construyeron en Francia durante el ochocientos, a causa de la irrupción de la fiebre amarilla, siguieron el modelo explicado. Muestra de ello son: el Hôpital Caroline, de Marsella; el lazareto Marie-Thérèse, de Burdeos o el de Mindin, en la desembocadura del Loira ${ }^{69}$. La difusión del modelo en otros países merece un estudio aparte ${ }^{70}$.

Fecha de recepción: 19 de abril de 2007.

Fecha de aceptación: 4 de junio de 2007.

67 Aunque es también probable que otros establecimientos de encierro influyeran en su configuración. Véase, por ejemplo, el plano de la prisión de Moscú que muestra Howard en el apéndice de su tratado sobre los hospitales y las prisiones - HowARD (1784), plancha IX - que es claramente pabellonario y muy parecido a la configuración final adoptada en los lazaretos.

68 Existe, además, un proyecto de principios del setecientos para el Royal Naval Hospital de Greenwich firmado por Sir Christopher Wren que coincide en casi todo con el modelo propuesto finalmente por la comisión francesa. Se puede ver en PEVSNER, N. (1979), Historia de las tipologías arquitectónicas. Barcelona: Gustavo Gili, p. 175.

69 Ver LAget (2002).

70 Para un estudio sobre la adopción de estas ideas en Canadá se puede consultar BONASTRA, Q. (2005), La cuarentena en Québec i el plan preventivo de William Marsden (18321866). Scripta Nova Revista Electrónica de Geografía y Ciencias Sociales, vol. VIII, nº 195 , 15 de agosto de 2005.En línea [http://www.ub.es/geocrit/sn/sn-195.htm] 